\title{
Primary Breast Lymphoma: Case Report Of A Rare Pathological Entity
}

\author{
Michael McFarlane, and Kathleen Coard
}

\begin{abstract}
Primary breast lymphoma is a rare disease, which accounts for $0.4 \%$ of all malignancies seen in the breast and $2 \%$ of extranodal lymphomas. The majority of cases are Bcell lymphomas, with diffuse large cell (B) lymphoma the predominant histological type. A variety of treatment modalities have been suggested, with radiation therapy recommended for stage I patients and chemotherapy recommended for stage II patients. Outcome following treatment is predicted by the pathological grade of the tumor and the presence of lymph node involvement. Radical surgical resection including mastectomy has not been shown to affect the outcome of this entity.

A 61-year-old woman presented with a one month history of a painful right breast lump. Examination identified the presence of two lumps which were biopsied, confirming the presence of a lymphocytic lymphoma expressing a B-cell phenotype with co-expression of CD 43 (MT-1) consistent with MALT-type lymphoma.

She underwent further excision for recurrent tumor but declined adjuvant therapy. She has remained disease free during a 7-year follow up period.

Primary breast lymphoma is a rare malignancy of the breast representing less than $2 \%$ of non-Hodgkin lymphoma. The features on clinical breast examination and imaging are not characteristic and cannot be differentiated from breast carcinoma. Treatment involves surgical resection with adjuvant chemotherapy and radiotherapy administered in selected cases.
\end{abstract}

Index Terms - breast; cancer; disease; female; malignancy.

\section{INTRODUCTION}

Primary breast lymphoma is a rare malignant lesion of the breast representing less than $0.5 \%$ of all malignant neoplasms of the breast and $1 \%$ to $2 \%$ of all non-Hodgkin lymphomas. (1) Few cases are reported in the literature, mainly small case series and retrospective reviews. The majority of lesions are B-cell lymphomas usually of the large cell type.

Clinical and radiological features are not characteristic of this disease and are similar to breast cancer. Treatment strategies include a range of modalities with surgery, radiotherapy and chemotherapy being the most commonly used.

\section{A. Case report}

This 61-year-old patient presented in July 2010 with a history of pain in the right breast, for a period of one month. She had also noted the presence of lumps in the same breast.

Published on June16, 2020

M. E. C. McFarlane, University of the West Indies, Jamaica.

(corresponding e-mail: michaelm500@yahoo.com)

K. C. M.Coard, University of the West Indies, Jamaica.
There was no significant past history and no family history of breast cancer.

Examination revealed a middle-aged female in no apparent distress. Her mucous membranes were pink and her vital signs were normal.

On examination of the right breast two ill-defined $3 \mathrm{~cm}$ diameter lumps were palpated in the upper outer quadrant. A provisional diagnosis of breast carcinoma was made and she was subjected to mammography and fine needle aspiration biopsy. The result of the fine needle biopsy showed lymphoid tissue but was not diagnostic. An incisional biopsy was subsequently performed and the histology confirmed the presence of a lymphocytic lymphoma expressing a Bcell phenotype with co-expression of CD 43 (MT-1) consistent with MALT-type lymphoma (Fig. 1, 2).

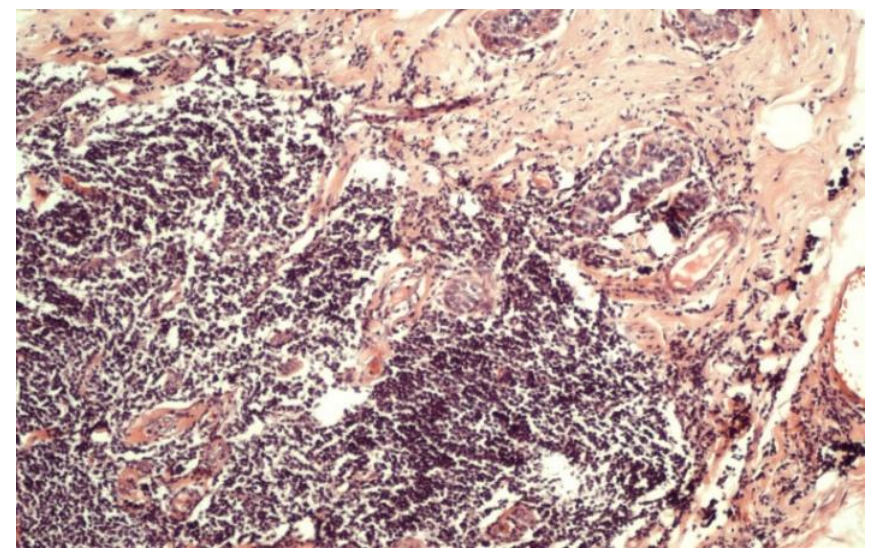

Fig.1. Low power photomicrograph of breast tissue containing a dense infiltrate of lymphocytes.

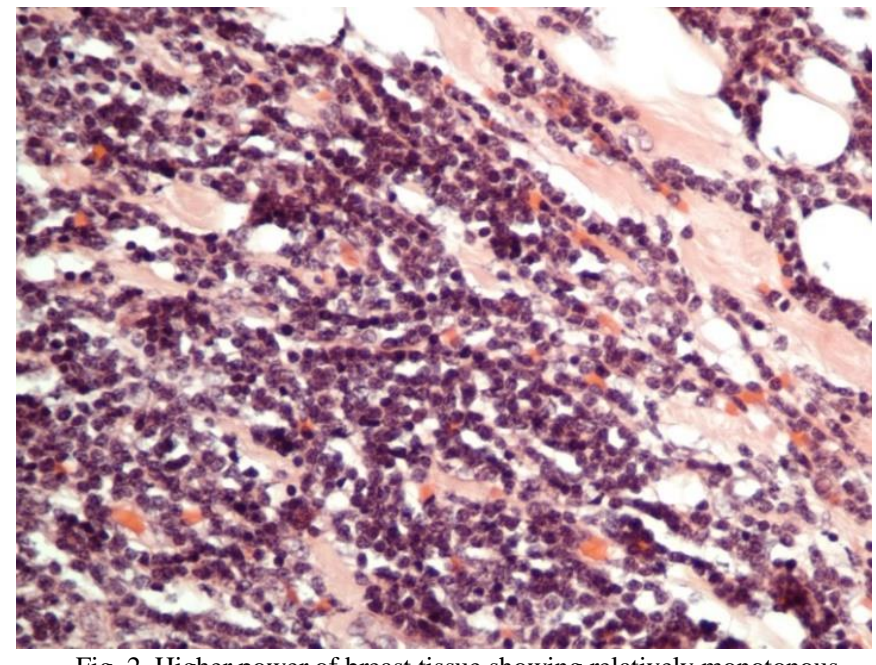

Fig. 2. Higher power of breast tissue showing relatively monotonous small lymphocytes with inconspicuous nucleoli.

Her postoperative course was uneventful. A PET scan at that time identified increased uptake in the right breast in 
keeping with residual tumor.

The patient returned 10 months later at which time a 3centimeter lump was discovered adjacent to the previous biopsy site in close proximity to the axillary tail. A wide local excision was performed with a $2 \mathrm{~cm}$ margin removing two lumps from the right breast. The histology again confirmed a non-Hodgkin's lymphoma of the breast. She was advised to have a course of radiotherapy and chemotherapy but declined further treatment and agreed only to follow-up clinical breast examination and mammography. She was seen at six monthly intervals with annual screening mammography. Follow up evaluation seven years after her first presentation revealed no evidence of recurrent disease.

\section{DISCUSSION}

Primary breast lymphoma (PBL) is a rare clinical entity accounting for less than $1 \%$ of all breast malignancies and $2 \%$ of extranodal lymphomas [1].

The description of Wiseman and Liao of this disease has remained the standard pathological definition for this condition [2]. The small volume of lymphatic tissue in the breast has also made this disease unique and pathological diagnosis depends on the identification of lymphomatous infiltration closely juxtaposed with mammary tissue, with no evidence of disease in non-breast locations. The origin of lymphatic tissue in the breast resulting in the formation of PBL has been questioned and likely sources may be lymphatic tissue adjacent to ducts and lobules or intramammary lymph nodes [3]. Mucosal-associated lymphoid tissue (MALT) may also be a source of PBL [4]. Patients with PBL must also not have had a previous diagnosis of lymphoma. The description proposed by Wiseman and Liao refers to two stages only, namely Stage I (lymphoma limited to the breast) and stage II (lymphoma confined to the breast and axillary nodes) with the exclusion of tumors that may have originated from other sites outside of the breast.

Wiseman and Liao also proposed criteria for PBL stating that the diagnosis should be considered when lymphoma of the breast presented as a local disease without extramammary disease within 6 months following the establishment of the diagnosis. Other criteria outlined included [1] having adequate tissue for histological diagnosis, [2] having mammary tissues and lymphomatous infiltrates in close proximity to each other, [3] showing no evidence of concurrent widespread disease, [4] having had no previous diagnosis of extrammary lymphoma[5].

The peak age incidence reported in previous studies is about 55 years with an age range of 17 to 90 years. [6] Analysis of the histological type of PBL has shown that diffuse large cell (B) lymphoma was the most common type. A review of the literature by Jennings of 213 cases that met World Health Organization classification criteria identified 102 cases $(47.9 \%)$ as diffuse large-cell lymphomas (B-cell lymphoma), 35 cases (15.5\%) were follicular lymphomas, $26(12.2 \%)$ were MALT type lymphomas, and 22 (10.3\%) Burkitt-like tumors. Overall 195 (91.5\%) of patients reported were listed as B-cell lymphomas and $14(6.6 \%)$ as being of T-cell type with only 4 patients indentified as
Hodgkin lymphoma [6].

Bilateral synchronous disease is rare and has been reported in $10 \%$ of patients with contralateral disease in up to $15 \%$ of patients [7]. There are no clinical features that differentiate PBL from a breast carcinoma or other breast pathology. The most common presentation is that of a lump which may raise the suspicion of a breast carcinoma. Many lumps are detected on clinical self-examination rather than on screening mammography.

In a review by Domchek et al, $91 \%$ of patients were diagnosed with PBL after the evaluation of a palpable mass, whereas screening mammography was almost useless in detecting the disease [8].

The patient presented in this report discovered the presence of a lump in the breast on clinical examination.

Skin involvement, nipple retraction and nipple discharge is uncommon in PBL and is seen mainly in high-grade lymphomas [9]. There is also a limited role for the use of radiological imaging investigations such as ultrasound or screening mammography.

No pathognomonic radiological features exist which allow differentiation of PBL from breast carcinoma. Ultrasound may identify a hypoechoic lesion with defined acoustic shadows that lack posterior enhancement.

Other modalities including magnetic resonance imaging and positron emission tomography [PET] may offer additional advantages in outlining the extent and number of lesions in the breast, the presence of lymphadenopathy and detection of recurrence [10].

The identification of a mass warrants biopsy. This may be performed by fine needle aspiration cytology, core needle biopsy or surgical biopsy. Core needle biopsy is preferred since it allows more accurate cell typing with the use of immunohistochemistry.

The treatment of PBL is controversial. Surgery, radiotherapy and chemotherapy have been recommended by most authors without consensus as to which of the modalities alone or in combination is suitable therapy for these patients. Surgical treatment varies from wide local excision to mastectomy. A review of the literature by Jennings showed that mastectomy alone offered no benefit in overall survival in patients with PBL or impact on the risk of recurrence [6]. Other reports also support not performing mastectomy for PBL and recommend radiotherapy and/or chemotherapy to effect adequate local control with improved survival and a reduction in recurrence rate [11, 12].

Dao et al [12] outlined an approach to the management of these patients, suggesting that patients with small PBL should undergo wide local excision followed by a course of radiotherapy. High-grade tumors including those with axillary nodal involvement should have both radiotherapy and chemotherapy to improve outcome. Mastectomy was not considered as first line therapy. Most authors now agree that if wide excision is feasible this should be the first approach since mastectomy does not affect the outcome [13, 14].

Radiotherapy may be used as adjunctive therapy to achieve better local control but is not recommended as the sole agent [12]. A wide range of radiotherapy doses to the breast, chest wall and axilla have been recommended. The 
range of doses reported varied between 1200 and $5500 \mathrm{cGY}$ with daily doses between 180 and $300 \mathrm{cGY}[12,15]$.

The most frequently used chemotherapy regimens in PBL include cyclophosphamide, vincristine, doxorubicin and prednisone commonly referred to as the CHOP regimen.

Miller et al have reported improved outcomes in patients with non-Hodgkins lymphoma by adding radiotherapy to 3 cycles of CHOP when compared with 8 cycles of $\mathrm{CHOP}$ alone [16]. Other authors have recommended 4 cycles of CHOP following radical surgery [13].

The use of the monoclonal antibody rituximab in combination with chemotherapy regimens for B-cell lymphomas has shown some promise in improving outcome but to date the usage of this agent has not been reported in patients with PBL [17].

Chemotherapy agents have also been administered by intrathecal injection to improve the prognosis of patients with aggressive forms of PBL as central nervous system (CNS) prophylaxis [18]. Although the reports of CNS relapse varies among different studies some authors recommend routine CNS prophylaxis in all patients diagnosed with PBL [19].

\section{CONCLUSIONS}

Primary breast lymphoma is a rare type of extranodal lymphoma which is often indistinguishable clinically from breast carcinoma. Because of the rarity of the disease and the range of treatment modalities, the optimal treatment approach is still in question. The majority of patients will benefit from limited surgical resection with the use of chemotherapy and/or radiotherapy in selected cases.

\section{REFERENCES}

[1] Topalovski M, Crisan D, Mattson JC. Lymphoma of the breast. A clinicopathologic study of primary and secondary cases. Arch Pathol Lab Med. 1999 Dec;123(12):1208-1

[2] Wiseman C, Liao KT. Primary lymphoma of the breast. Cancer. 1972 Jun;29(6):1705-12.

[3] Ferguson DJ. Intraepithelial lymphocytes and macrophages in the normal breast.Virchows Arch A Pathol Anat Histopathol 1985;407(4):369-78.

[4] Kim SH, Ezekiel MP, Kim RY. Primary lymphoma of the breast: breast mass as an initial symptom. Am J Clin Oncol. 1999 Aug;22(4):381-3.

[5] Gholam D, Bibeau F, ElWeshi A, Bosq J, Ribrag V.Primary breast lymphoma. Leuk Lymphoma.2003;44(7):1173-1178.

[6] Jennings WC, Baker RS, Murray SS, Howard CA, Parker DE, Peabody LF, Vice HM,Sheehan WW, Broughan TA. Primary breast lymphoma: the role of mastectomy and the importance of lymph node status. Ann Surg. 2007 May;245(5):784-9

[7] Vardar E, Ozkok G, Cetinel M, Postaci H. Primary breast lymphoma cytologic diagnosis. Arch Pathol Lab Med. 2005 May;129(5):694-6

[8] Domchek SM, Hecht JL, Fleming MD, Pinkus GS, Canellos GP. Lymphomas of the breast: primary and secondary involvement. Cancer. 2002 Jan 1;94(1):6-13.

[9] Sabaté JM, Gómez A, Torrubia S, Camins A, Roson N, De Las Heras P, Villalba-Nuño V. Lymphoma of the breast: clinical and radiologic features with pathologic correlation in 28 patients. Breast J. 2002 Sep-Oct;8(5):294-304.

[10] Mavromatis BH, Cheson BD. Pre- and post-treatment evaluation of non-Hodgkin's lymphoma. Best Pract Res Clin Haematol. 2002 Sep;15(3):429-47.

[11] Dao AH, Adkins RB Jr, Glick AD. Malignant lymphoma of the breast: a review of 13 cases.Am Surg.1992 Dec;58(12):792-6.

[12] Babovic N, Jelic S, Jovanovic V. Primary non-Hodgkin lymphoma of the breast. Is it possible to avoid mastectomy? J Exp Clin Cancer Res. 2000 Jun;19(2):149-54.
[13] Uesato M, Miyazawa Y, Gunji Y, Ochiai T. Primary non-Hodgkin's lymphoma of the breast: report of a case with special reference to 380 cases in the Japanese literature. Breast Cancer. 2005;12(2):1548. Review.

[14] Radkani P, Joshi D, Paramo JC, Mesko TW. Primary breas lymphoma: 30 years of experience with diagnosis and treatment at a single medical center. JAMA Surg.2014 Jan;149(1):91-3. doi: 10.1001/jamasurg.2013.2283.

[15] Jeanneret-Sozzi W, Taghian A, Epelbaum R, Poortmans P, Zwahlen D, Amsler B, Villette S, Belkacémi Y, Nguyen T, Scalliet P, Maingon P, Gutiérrez C, Gastelblum P, Krengli M, Raad RA Ozsahin M, Mirimanoff RO. Primary breast lymphoma: patient profile, outcome and prognostic factors. A multicentre Rare Cancer Network study. BMC Cancer. 2008 Apr 1;8:86. doi: 10.1186/14712407-8-86.

[16] Miller TP, Dahlberg S, Cassady JR, Adelstein DJ, Spier CM, Grogan TM, LeBlanc M, Carlin S, Chase E, Fisher RI. Chemotherapy alone compared with chemotherapy plus radiotherapy for localized intermediate- and high-grade non-Hodgkin's lymphoma. N Engl J Med. 1998 Jul 2;339(1):21-6.

[17] Coiffier B, Lepage E, Briere J, Herbrecht R, Tilly H, Bouabdallah R, Morel P,Van Den Neste E, Salles G, Gaulard P, Reyes F, Lederlin P, Gisselbrecht C. CHOP chemotherapy plus rituximab compared with CHOP alone in elderly patients with diffuse large-B-cell lymphoma. N Engl J Med. 2002 Jan 24;346(4):235-42.

[18] Joks M, Myśliwiec K, Lewandowski K. Primary breast lymphoma a review of the literature and report of three cases. Arch Med Sci. $2011 \mathrm{Feb} ; 7(1): 27-33$.

[19] Avilés A, Delgado S, Nambo MJ, Neri N, Murillo E, Cleto S Primary breast lymphoma: results of a controlled clinical trial. Oncology. 2005;69(3):256-60. Epub 2005 Sep 15. 